\title{
sciendo
}

\section{ANALYSIS OF THE METHYLATION STATUS OF CpG SITES WITHIN CANCER-RELATED GENES IN EQUINE SARCOIDS*}

\author{
Ewelina Semik-Gurgul ${ }^{1 \star}$, Tomek Ząbek ${ }^{1}$, Agnieszka Fornal ${ }^{1}$, Artur Gurgul $^{1}$, Klaudia Pawlina-Tyszko ${ }^{1}$, \\ Jolanta Klukowska-Rötzler ${ }^{2,3}$, Monika Bugno-Poniewierska ${ }^{1,4}$ \\ ${ }^{1}$ Department of Animal Molecular Biology, National Research Institute of Animal Production, \\ 32-083 Balice n. Kraków, Poland \\ ${ }^{2}$ Swiss Institute of Equine Medicine, ALP-Haras, University of Berne, Länggasstrasse 124, \\ Postfach 8466, Berne CH-3001, Switzerland \\ ${ }^{3}$ Department of Emergency Medicine, University Hospital Bern, Inselspital, 3010 Bern, Switzerland \\ (Present address) \\ ${ }^{4}$ Institute of Veterinary Sciences, University of Agriculture in Krakow, \\ Al. Mickiewicza 24/28, 30-059 Kraków, Poland (Present address) \\ •Corresponding author: ewelina.semik@izoo.krakow.pl
}

\begin{abstract}
In the recent years, particular attention was given to the research aimed at optimizing the use of tumour epigenetic markers. One of the best known epigenetic changes associated with the process of carcinogenesis is aberrant DNA methylation. The aim of the present research was to evaluate the methylation profile of genes potentially important in the diagnosis and/or prognosis of equine sarcoids, the most commonly detected skin tumours in Equidae. The methylation status of potential promoter sequences of nine genes: $A P C, C C N D 2, C D K N 2 B, D C C, R A R \beta, R A S S F 1, R A S S F 5$, THBS1 and TRPM1, was determined using bisulfite sequencing polymerase chain reaction (BSPCR). The results of this study did not reveal any changes in the level of DNA methylation in the analysed group of candidate genes between the tumour and healthy tissues. Despite numerous reports describing the aberrant methylation of the promoters of the analysed genes in human cancers, the data obtained did not confirm the existence of such relationships in the examined tumour tissues, which excludes the possibility of using these genes for the diagnosis of the equine sarcoid.
\end{abstract}

Key words: equine sarcoids, horse, tumourigenesis, DNA methylation, BSPCR

Sarcoids are among the most commonly diagnosed skin tumours in Equidae species. It is widely accepted that bovine papillomavirus (BPV) types 1 and 2

*Funding for this study was provided by the National Research Institute of Animal Production, Balice, Poland. Research Project No. 04-008.1. 
are recognised as aetiological factors of sarcoid disease (Chambers et al., 2003). Recent research also indicates a possible contribution of type 13 (BPV13) to the sarcoids pathogenesis (Lunardi et al., 2013). While sarcoids are not fatal, their nodular form contributes to mechanical damage, which may cause discomfort and impede the use of affected horses, thus affecting a horse's value and causing considerable economic losses for their owners. What is more, progression of the diseased tissue may result in ulceration, contribute to infection and, depending on the location of lesions, cause permanent impairment of motor function (Broström, 1995). Today, histological examination of sarcoids is considered the most reliable diagnostic procedure. Despite the fact that immunohistochemical methods belong to the most commonly used methods in the cancer diagnosis, they are not fully effective, especially in case of differentiation between deep dermal or subcuticular equine sarcoids (ie, nodular sarcoids) and other spindle cell tumours in the dermis and subcutis such as peripheral nerve sheath tumours (Bogaert et al., 2011; Epperson and Castleman, 2017). Moreover, they are time consuming and require the use of organic solvents, often harmful to human health. Therefore, new diagnostic strategies are being sought that enable rapid and accurate diagnosis.

In the recent years, particular attention was given to the research aimed at optimizing the use of tumour epigenetic cancer markers. One of the best known epigenetic changes associated with the process of carcinogenesis is aberrant DNA methylation. Local hypermethylation of $\mathrm{CpG}$ islands critical to the neoplastic transformation process is mainly associated with the promoter regions of tumour suppressor genes (TSG). These are primarily genes of proteins involved in cell cycle regulation, apoptosis regulation, and DNA repair, but also other genes whose protein products contribute to processes such as differentiation, angiogenesis, detoxication, and drug resistance (Das and Singal, 2004).

Determination of the epigenetic changes may serve as a tool to develop panels of genes, in which promoter methylation may be correlated with the incidence of a disease. By way of example, a study of Melnikov et al. (2014) allowed assembling a panel of methylation biomarkers (BRCA1, CCND2, CDKN1A, GSTP, MYF3, RPL15 and TRANCE), which could be used to diagnose squamous cell carcinoma (SCC), the second most frequent skin cancer in humans. Furthermore, hypermethylation of some TSG is associated with poorer prognosis in different cancer types. For example, hypermethylation of the THBS1 promoter region was detected in solid tumour brain metastases, such as melanoma or lung cancer (Gonzalez-Gomez et al., 2004).

Identification of changes that occur in DNA methylation can broaden our knowledge about molecular changes occurring during sarcoid genesis as well as could be used as the basis for developing novel alternative diagnostic approaches and therapeutic approaches in sarcoid treatment. Therefore, the objective of the present study was to examine the methylation profile for a panel of nine genes (APC, CCND2, $C D K N 2 B, D C C, R A R \beta, R A S S F 1, R A S S F 5$, THBS1 and TRPM1) tested for epigenetic silencing, resulting from hypermethylation of cancer suppressor genes in different types of human tumours. The criterion for choosing the genes was the documented 
contribution of the products of these genes to processes such as cell cycle regulation, DNA repair and proliferation as well as the earlier data linking them to two types of human skin cancers - melanoma, the most common malignant tumour of melanocytes and squamous cell carcinoma (SCC) in which virus from Papillomaviridae family, similar to horse sarcoids, play an important role as the possible aetiological factor (Spugnardi et al., 2003; Furuta et al., 2004; Hoon et al., 2004; Maruya et al., 2004; Chen et al., 2007; Carvalho et al., 2008; Bonazzi et al., 2011; Lindner et al., 2013; Melnikov et al., 2014).

\section{Material and methods}

\section{Material}

The study material was obtained from the Veterinary Clinic at the University of Bern, Switzerland. Six horses diagnosed with sarcoids were analysed. From each individual, two tissue samples were collected at different sites: tumour tissue (L) and the tumour-distant skin (D), sampled from the unaffected region of normal skin. DNA was isolated from tissue using a DNeasy Blood \& Tissue kit (Qiagen, Germany), converted with sodium bisulfite using Epitec Bisulfite Conversion Kit (Qiagen) and amplified with EpiTect Whole Bisulfitome Kit (Qiagen), following the manufacturer's instructions.

\section{Bisulfite sequencing (BSPCR)}

A panel of nine candidate genes ( $A P C, C C N D 2, C D K N 2 B, R A R \beta, R A S S F 1$, RASSF5, THBS1, TRPM1, DCC), examined for DNA methylation level in different types of human cancer, was selected for the analyses. The potential promoter regions were identified with the MatInspector (Genomatix) program. Fragments of the selected regions were amplified with BSPCR primers designed in $\mathrm{CpG}$ island flanking regions using Methyl Primer Express ${ }^{\circledR}$ Software v1.0 (Applied Biosystems Software) (Table 1). HotStarTaq ${ }^{\circledR}$ polymerase (Qiagen) was used for the amplification. The touchdown PCR cycling conditions were: $95^{\circ} \mathrm{C}$ for $15 \mathrm{~min}$, followed by 5 cycles at $97^{\circ} \mathrm{C}$ for $5 \mathrm{sec}, 62$ or $58^{\circ} \mathrm{C}$ for $2 \mathrm{~min}$ and $72^{\circ} \mathrm{C}$ for $45 \mathrm{sec}$, and further 35 cycles at $97^{\circ} \mathrm{C}$ for $5 \mathrm{sec}, 60$ or $56^{\circ} \mathrm{C}$ for $2 \mathrm{~min}, 72^{\circ} \mathrm{C}$ for $45 \mathrm{sec}$ and the final elongation at $72^{\circ} \mathrm{C}$ for $7 \mathrm{~min}$. To purify BSPCR products from excess primers and deoxyribonucleotides, a combination of two enzymes: shrimp alkaline phosphatase (FastAPтм Thermosensitive Alkaline Phosphatase, SAP, Thermo Fisher Scientific, USA) and E. coli exonuclease I (Exo I, Thermo Fisher Scientific) was used. The sequencing was performed using BigDye ${ }^{\circledR}$ Terminator v3.1 Cycle Sequencing Kit (Thermo Fisher Scientific). 
Table 1. Primer sequences used for amplification of regions analysed with BSPCR technique

\begin{tabular}{|c|c|c|c|c|}
\hline Locus & $\begin{array}{c}\text { Accession } \\
\text { number }\end{array}$ & $\begin{array}{c}\text { Number } \\
\text { of analysed } \\
\text { CpG site }\end{array}$ & Primer sequences & $\begin{array}{l}\text { Size } \\
\text { of PCR } \\
\text { products }\end{array}$ \\
\hline$A P C$ & NM_001301314 & 24 & $\begin{array}{l}\text { F 5' TTTGTTAATTTGTTTGTTTTGTGG 3' } \\
\text { R 5' AACCCAACAACACCTCCAT 3' }\end{array}$ & $362 \mathrm{bp}$ \\
\hline$C C N D 2$ & NM_001309189 & 10 & $\begin{array}{l}\text { F 5' TGGGTAGGAGTGTTAGGATTAG 3' } \\
\text { R 5' AACAATTAACTCTCСТCССТCT 3' }\end{array}$ & 379 bp \\
\hline$C D K N 2 B$ & XM_001496235 & 12 & $\begin{array}{l}\text { F 5' TTAGTGGGTGGGAGGAGT 3' } \\
\text { R 5' AACCCAAACRCAAACTAAC 3' }\end{array}$ & $450 \mathrm{bp}$ \\
\hline$R A R \beta$ & XM_001494115 & 8 & $\begin{array}{l}\text { F 5' GGTTGTTTGTTTTTGTAGGG 3' } \\
\text { R 5' ATACCCAAACAAACCCTACC 3' }\end{array}$ & $306 \mathrm{bp}$ \\
\hline$R A S S F 1$ & XM_014731655 & 29 & $\begin{array}{l}\mathbf{F} \text { 5' TTTGTGAGGTTGAGTTGAG 3' } \\
\mathbf{R} \text { 5' TCСТCCTAACTACAATAACCACTA 3' }\end{array}$ & $352 \mathrm{bp}$ \\
\hline RASSF5 & XM_001491727 & 50 & $\begin{array}{l}\text { F 5' GTGGTTTTYGAATTGTTTTG 3' } \\
\text { R 5' CCACTACTCATACTACTATCCACC 3' }\end{array}$ & $445 \mathrm{bp}$ \\
\hline THBS1 & NM_001308952 & 37 & $\begin{array}{l}\text { F 5' TGAGAAGTTTTAGGGTTTTTG 3' } \\
\text { R 5' CCCAAAAATCCCTTACCTATA 3' }\end{array}$ & $394 \mathrm{bp}$ \\
\hline TRPM1 & XM_005602846 & 5 & $\begin{array}{l}\mathbf{F} \text { 5' TTTGGTGGGTATAGGGTTAAG 3' } \\
\mathbf{R} \text { 5' AATCTCCTAAACTCACCTCACA 3' }\end{array}$ & $391 \mathrm{bp}$ \\
\hline$D C C$ & XM_014727646 & 6 & $\begin{array}{l}\text { F 5' TTAGGAAATAGTGGTTTGGTATTT 3' } \\
\text { R 5' CAAAAAACTTCCAACAACTACA 3' }\end{array}$ & $365 \mathrm{bp}$ \\
\hline
\end{tabular}

\section{Analysis of BSPCR results}

The obtained sequencing chromatograms were inspected using FinchTV v1.4.0 software (Geospiza Inc.) to reject low quality reads. The program was also used for qualitative analysis of DNA methylation whereby the presence or absence of DNA methylation in DNA sequence was identified by determining the cytosine or thymidine in $\mathrm{CpG}$ sites. Following the analysis of chromatograms, the sequences were compared with the horse genome reference sequence and visualized by BISMA software (Rohde et al., 2010). To quantify the level of $\mathrm{CpG}$ sequence methylation, the Mquant method described by Leakey et al. (2008) was used.

Statistical significance of differences in the level of DNA methylation between lesional and tumour-distant skin sample groups was determined using Wilcoxon non-parametric test or parametric t-test after distribution evaluation using the Shapiro-Wilk normality test (R Development Core Team, 2011). 


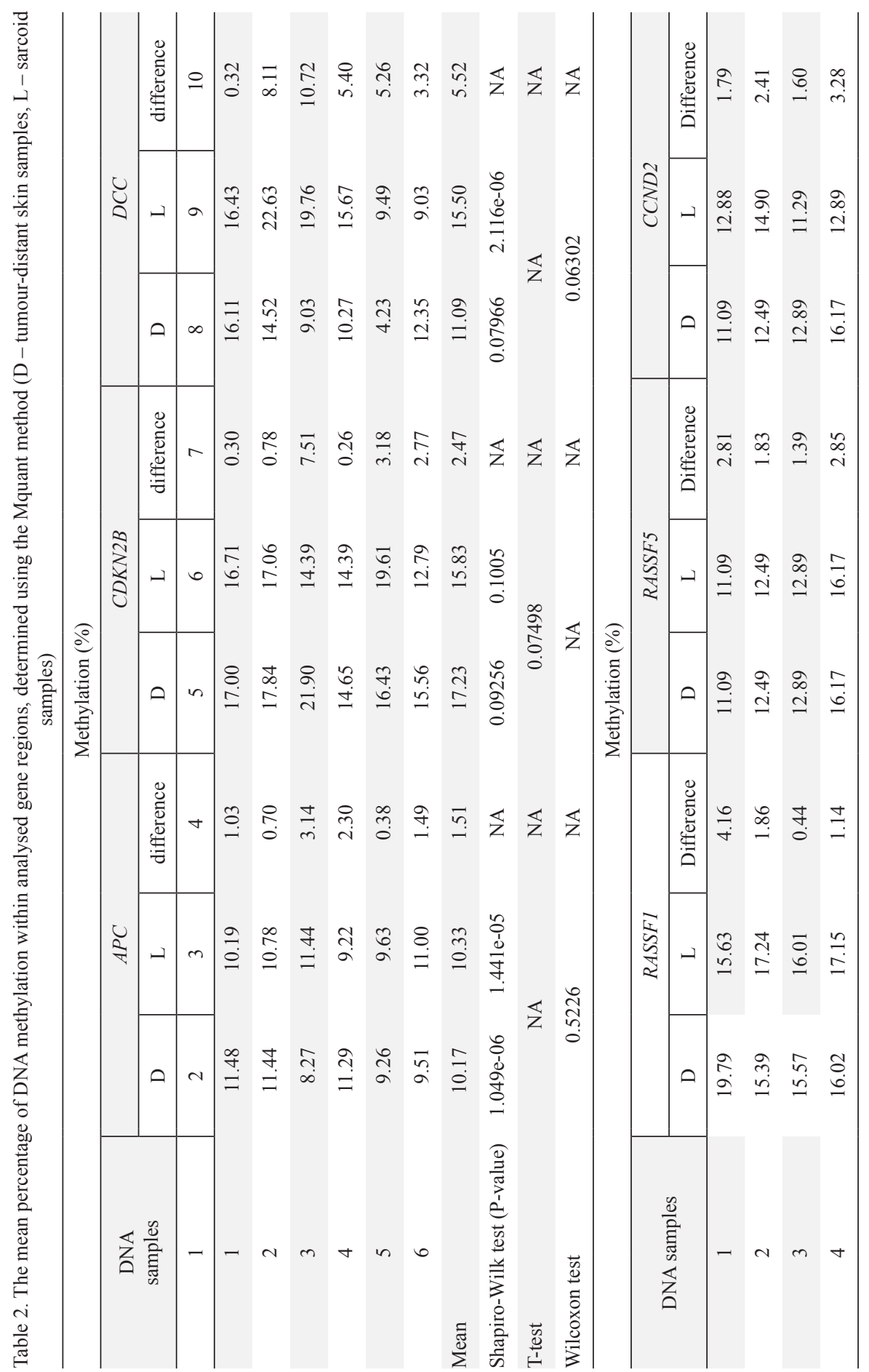




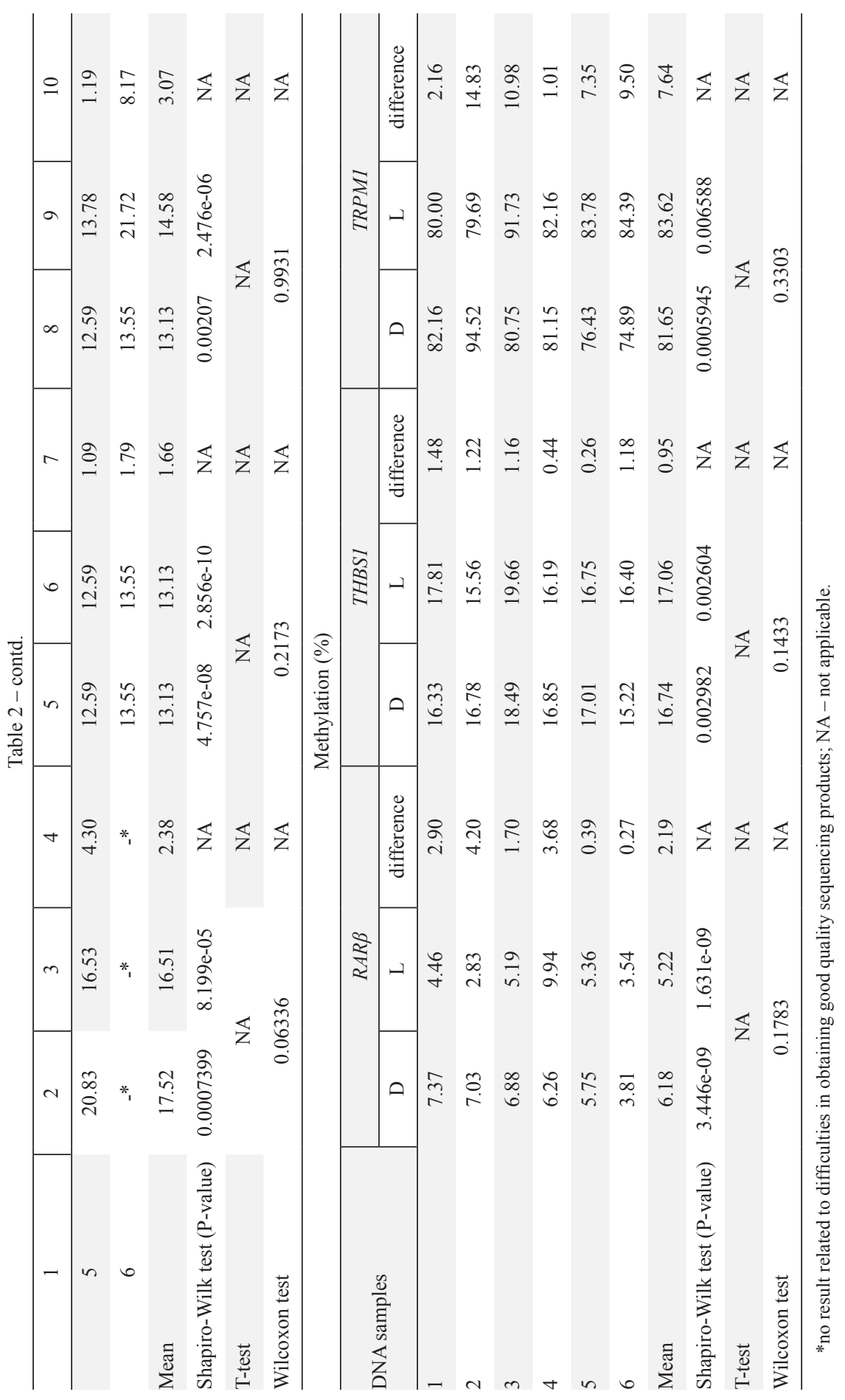




\section{Results}

The DNA methylation profile of $181 \mathrm{CpG}$ sites located within potential regulatory regions of the nine candidate genes (APC, CCND2, CDKN2B, RAR, RASSF1, RASSF5, THBS1, TRPM1, DCC) was analysed in DNA samples obtained from six sarcoids and six tumour-distant skin samples. The analysis of BSPCR sequencing results showed no significant differences in the level of $\mathrm{CpG}$ sequences methylation between the healthy and tumour tissues, in any of the gene fragments under analysis $(\mathrm{P}>0.05)$ (Table 2). The results revealed high level of methylation (from 74.89 to $94.52 \%$ per sample with a mean of $81.65 \% \pm 16.69 \mathrm{SD}$ within control (D) group and from 79.69 to $91.73 \%$ with a mean of $83.62 \% \pm 11.62$ SD within sarcoid (L) group) of sites in TRPM1 promoter region and low level of methylation (range from $3.81-6.88 \%$, mean of $6.18 \% \pm 9.76 \mathrm{SD}$ for $R A R \beta$ region within control (D) group to $15.57-20.83 \%$, mean of $17.52 \% \pm 10.88 \mathrm{SD}$ for $R A S S F 1$ region within control (D) group) in the promoter regions of the other genes (Figure 1 and 2). Application of the Mquant method proved the same trend in DNA methylation for the analysed tumour and skin samples as well as a similar DNA methylation percentage (differences between groups ranged from $0.30 \%$ to $14.83 \%$ and were statistically insignificant). Detailed results of the methylation analysis for all the gene fragments are provided in the Table 2.
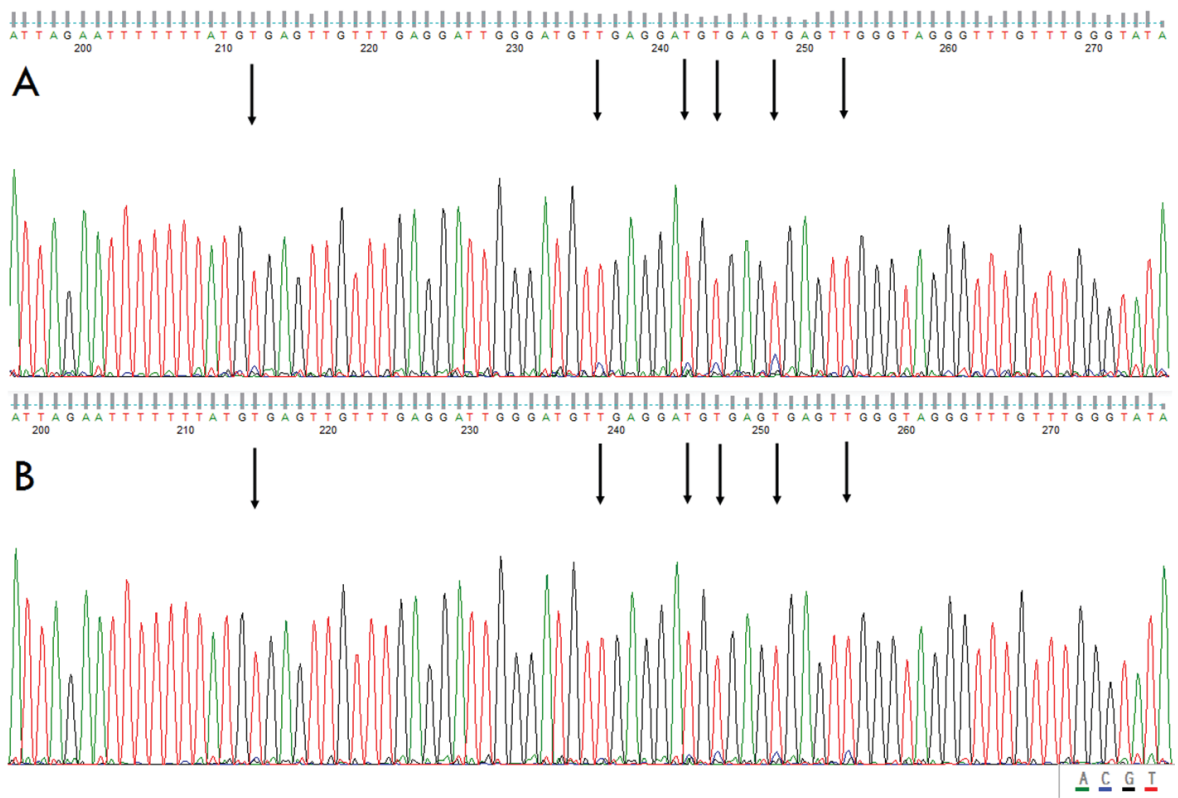

Figure 1. A fragment of the chromatogram of the $R A R \beta$ promoter region indicating the absence of differences in the $\mathrm{CpG}$ methylation pattern between the sarcoid and healthy tissue samples (A - tumour distant skin (5D), B - sarcoid (5L); black arrows indicate $\mathrm{CpG}$ sites where cytosine was converted by bisulfite) 


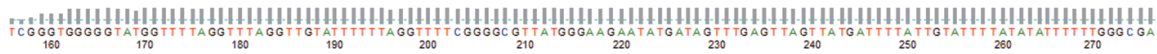
$\downarrow$ A $\downarrow \downarrow$
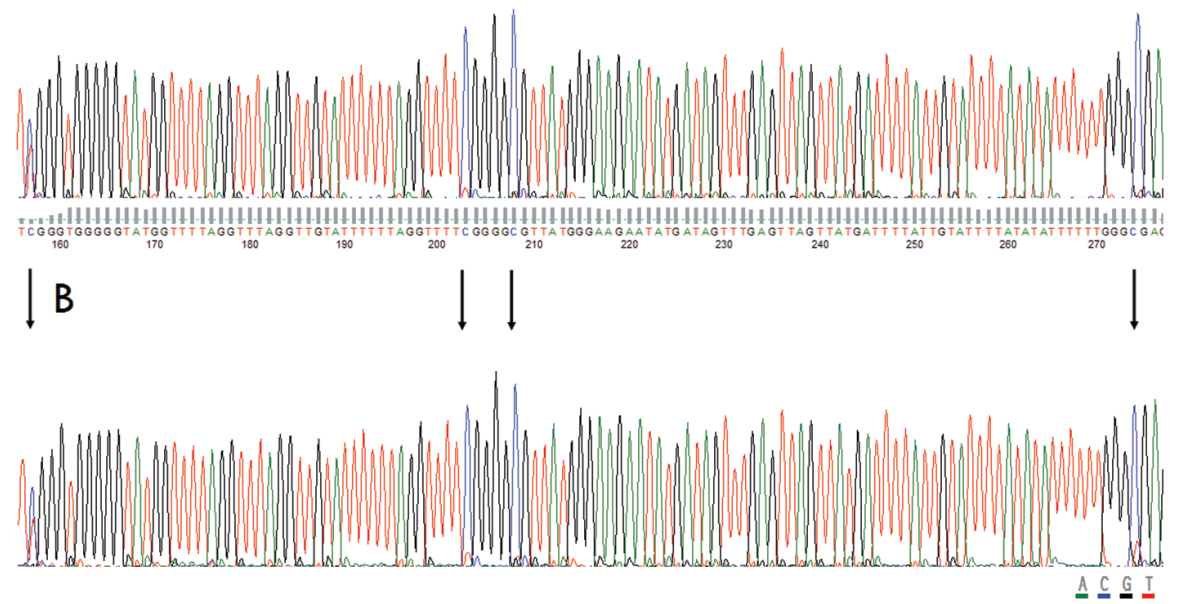

Figure 2. A fragment of the chromatogram of the TRPM1 promoter region indicating the absence of differences in the $\mathrm{CpG}$ methylation pattern between the sarcoid and healthy tissue samples (A - tumour distant skin (1D), B - sarcoid (1L); black arrows indicate CpG sites where cytosine was not converted by bisulfite)

\section{Discussion}

Research to date has shown that changes in the normal function of some genes have a significant role in various pathological processes, including tumour progression. Aberrant APC (Adenomatous Polyposis Coli) gene promoter methylation is one of the epigenetic changes observed in colon (Agrawal et al., 2007), lung (Virmani et al., 2001; Esteller, 2005) and prostate cancers (Esteller, 2005). Similarly, aberrant methylation of CCND2 (Cyclin D2) gene involved in cell cycle regulation, differentiation and neoplastic transformation, was found in numerous human cancers (Evron et al., 2001; Oshimo et al., 2003; Furuta et al., 2004; Melnikov et al., 2014). In turn, aberrant methylation of the promoter of the CDKN2B (Cyclin-Dependent Kinase Inhibitor $2 \mathrm{~B}$ ), apart from inactivation due to mutation, was observed in many haematological cancers, in myelodysplastic syndrome (MDS) and in acute myeloid leukaemia (AML) (Christiansen et al., 2003; Boultwood and Wainscoat, 2007). The DCC (DCC Netrin 1 Receptor) gene is a tumour suppressor whose inactivation by DNA methylation is correlated with the incidence and poor prognosis of oral squamous cell carcinoma (Ogi et al., 2002). In the case of $R A R \beta$ (Retinoic Acid Receptor, Beta) gene, the findings of Fendri et al. (2009) may indicate that methylation of this gene could be associated with the prevalence of highly differentiated tumours and the advanced stages of tumourigenesis. Genes of the RASSF (Ras Association (RalGDS/ AF-6) Domain Family) gene family, have been frequently described in the study of the 
epigenetic inactivation of genes in human cancers. For example, hypermethylation of the RASSF $1 A$ promoter region, was correlated with tumour stage and poor prognosis (Lee et al., 2001; Maruyama et al., 2001; Chan et al., 2003) and RASSF5 gene aberrant methylation, was shown in kidney and lung, liver, and neuroblastoma tumour cell lines (Djos et al., 2012). The THBS1 (Thrombospondin 1) gene is the first identified natural inhibitor of angiogenesis. However, the mechanisms controlling the expression of this gene are not completely understood. One possible mechanism is DNA methylation, which has been confirmed in glioma studies (Li et al., 1999). The protein product of the TRPM1 (Transient Receptor Potential Cation Channel, Subfamily M, Member 1) gene is most likely involved in the regulation of melanocyte physiology. Expression of this protein is inversely correlated with melanoma aggressiveness and used as a prognostic marker for melanoma metastases (Guo et al., 2012).

The main focus of the present study was to determine differences in the methylation level of potential promoter regions of candidate genes, between the sarcoid tissue and the healthy (control) tissue. The differences in methylation were identified by determining, in bisulfite-converted DNA, the sites indicative of differential methylation. The analysis of the sequencing results revealed methylation of the potential promoter region of the TRPMI gene as well as the absence of methylation for $\mathrm{CpG}$ sequences of the other gene fragments in both tissues. Despite the numerous reports describing the abnormal methylation of the promoters of the analysed genes in human tumours, the data obtained failed to confirm these differences in the biological material under study. It can be then speculated that the analysed genes probably play no significant role in equine sarcoid progression. The literature data concerning DNA methylation and its importance in response to the treatment of animal tumours is scarce. To date, the analysis of the methylation of gene promoter sequences in horse sarcoids has been performed by one research team (Altamura et al., 2012; Strazzullo et al., 2012). Their study concerning the analysis of the methylation of regulatory sequences of the FHIT (Fragile Histidine Triad) and MGMT (O-6-methylguanineDNA Methyltransferase) genes, which are often silenced by epigenetic processes in a large number of human tumours, also did not confirm considerable differences in the methylation level of this genes between the horse sarcoid tissue and the healthy control tissue. However, they found the decreased MGMT and FHIT expression in the sarcoid tissue which could suggest involvement of epigenetic mechanisms.

The results of this study did not reveal any changes in the level of DNA methylation in the analysed group of nine candidate genes between the tumour and tumourdistant skin tissues. At the same time, at this stage of research, it is concluded that DNA methylation of the APC, CCND2, CDKN2B, RAR $\beta, R A S S F 1, R A S S F 5, T H B S 1$, $T R P M 1$ and $D C C$ genes is not a significant factor in the progression of equine sarcoids. Future research is needed to more clearly evaluate the role of aberrant methylation in the genesis and progression of equine sarcoids.

\section{Ethics approval}

The sample collection for this study was approved by the Animal Experimentation Ethics Committee of the Canton of Berne, Switzerland (BE 30/11; 11 April 2011). 


\section{References}

Agrawal A., Murphy R.F., Agrawal D.K. (2007). DNA methylation in breast and colorectal cancers. Mod. Pathol., 20: 711-721.

A lt a mura G., Strazzullo M., Corteggio A., Francioso R., Roperto F., D'Espos to M., B orzac ch i e 11 o G. (2012). O(6)-methylguanine-DNA methyltransferase in equine sarcoids: molecular and epigenetic analysis. BMC Vet. Res., 8: 218.

Bogaert L., van Heerden M., de Cock H.E.V., Martens A., Chiers K. (2011). Molecular and immunohistochemical distinction of equine sarcoid from schwannoma. Vet. Pathol., 48: 737-741.

B onazzi V.F., Nancarrow D.J., Stark M.S., Moser R.J., B oyle G.M., A oude L.G., S chmidt C., Hayw ard N.K. (2011). Cross-platform array screening identifies COL1A2, THBS1, TNFRSF10D and UCHL1 as genes frequently silenced by methylation in melanoma. PLoS One, 6:e26121.

B o u ltw o od J., Wain s c o at J.S. (2007). Gene silencing by DNA methylation in haematological malignancies. Brit. J. Haematol., 138: 3-11.

B roström H. (1995). Equine sarcoids. A clinical and epidemiological study in relation to equine leucocyte antigens (ELA). Acta Vet. Scan., 36: 223-236.

C a rv a 1 h o A.L.,J e r on i m o C.,K i m M.M.,H e n ri qu e R.,Z h a n g Z.,H o qu e M.O.,Ch a n g S., Brait M., Nayak C.S., Jiang W.W., Claybourne Q., Tokumaru Y., Lee J., Goldenberg D., Garrett-Mayer E., Goodman S., Moon C.S., Koch W., Wes tra W.H., Sidransky D., C a lifan o J.A. (2008). Evaluation of promoter hypermethylation detection in body fluids as a screening/diagnosis tool for head and neck squamous cell carcinoma. Clin. Cancer Res., 14: 97-107.

Cha mbers G., E 11 s m ore V.A., O'Brien P.M., R eid S.W.J., L ove S., C a m p o M.S., N a s ir L. (2003). The association of bovine papillomavirus with equine sarcoids. J. Gen. Virol., 84: 1055-1062.

Chan M.W., Chan L.W., Tang N.L., Lo K.W., Tong J.H., Chan A.W., Cheung H.Y., Wong W.S., Chan P.S., La i F.M., To K.F. (2003). Frequent hypermethylation of promoter region of RASSF1A in tumor tissues and voided urine of urinary bladder cancer patients. Int. J. Cancer., 104: 611-616.

Chen K., Sawhney R., Khan M., B enninger M.S., Hou Z., S e thi S., S te phen J.K., Worsham M.J. (2007). Methylation of multiple genes as diagnostic and therapeutic markers in primary head and neck squamous cell carcinoma. Arch. Otolaryngol. Head Neck Surg., 133: 1131-1138.

Christiansen D.H., Andersen M.K., Pedersen-Bjergaard J. (2003). Methylation of p15INK4B is common, is associated with deletion of genes on chromosome arm $7 \mathrm{q}$ and predicts a poor prognosis in therapy-related myelodysplasia and acute myeloid leukemia. Leukemia, 17: 1813-1819.

D a s P.M., S in g a l R. (2004). DNA methylation and cancer. J. Clin. Oncol., 22: 4632-4642.

Djos A., Martins o n T., Kogner P., Carén H. (2012). The RASSF gene family members RASSF5, RASSF6 and RASSF7 show frequent DNA methylation in neuroblastoma. Mol. Cancer, 11: 40 .

E p pers on E.D., Ca s t le m a n W.L. (2017). Bovine papillomavirus DNA and S100 profiles in sarcoids and other cutaneous spindle cell tumors in horses. Vet. Pathol., 54: 44-52.

Es te 11 er M. (2005). Aberrant DNA methylation as a cancer-inducing mechanism. Annu. Rev. Pharmacol. Toxicol., 45: 629-656.

Evron E., Umbricht C.B., Korz D., Raman V., Loeb D.M., Niranjan B., Buluwe 1 a L., We itzman S.A., Marks J., Sukumar S. (2001). Loss of cyclin D2 expression in the majority of breast cancers is associated with promoter hypermethylation. Cancer Res., 61: 2782-2787.

Fendri A., Masmoudi A., Khabir A., Sellami-Boudawara T., Daoud J., Frikha M., Ghorbel A., Gargouri A., Mokdad-G argouri R. (2009). Inactivation of RASS$F 1 A$, RARßeta2 and DAP-kinase by promoter methylation correlates with lymph node metastasis in nasopharyngeal carcinoma. Cancer Biol. Ther., 8: 444-451. 
Furuta J., Umebayashi Y., Miyamoto K., Kikuchi K., Otsuka F., Sugimura T., Us h i j i m a T. (2004). Promoter methylation profiling of 30 genes in human malignant melanoma. Cancer Sci., 95: 962-968.

Gonzalez-Gomez P., B e1lo M.J., Alonso M.E., Amiñoso C., Lopez-Marin I., De Campos J.M., I s la A., Gutierrez M., Rey J.A. (2004). Promoter methylation status of multiple genes in brain metastases of solid tumors. Int. J. Mol. Med., 13: 93-98.

Gu o H., C a r l s o n J.A., S l o m in s k i A. (2012). Role of TRPM in melanocytes and melanoma. Exp. Dermatol., 21: 650-654.

H o o n D.S., S pugnard i M., K u o C., Hu ang S.K., Morton D.L., Ta b a c k B. (2004). Profiling epigenetic inactivation of tumor suppressor genes in tumors and plasma from cutaneous melanoma patients. Oncogene, 23: 4014-4022.

Le a ke y T., Zi el insk i J., S i e g fri ed R.N., S i e gel E.R., F a n C.Y., C o on e y C.A. (2008). A simple algorithm for quantifying DNA methylation levels on multiple independent CpG sites in bisulfite genomic sequencing electropherograms. Nucleic Acids Res., 36: e64.

L e e M.G., Kim H.Y., B y un D.S., L e e S.J., Lee C.H., Kim J.I., Chang S.G., Chi S.G. (2001). Frequent epigenetic inactivation of RASSF1A in human bladder carcinoma. Cancer Res., 61: 6688-6692.

Li Q., A huj a N., B urger P.C., I s s a J.P. (1999). Methylation and silencing of the Thrombospondin-1 promoter in human cancer. Oncogene, 18: 3284-3289.

Lindner D.J., Wu Y., Haney R., J a c obs B.S., Fruehauf J.P., Tuthill R., B orden E.C. (2013). Thrombospondin-1 expression in melanoma is blocked by methylation and targeted reversal by 5-Aza-deoxycytidine suppresses angiogenesis. Matrix Biol., 32: 123-132.

Lunardi M., de A l cântara B.K., Otonel R.A., Rodrigues W.B., Alfieri A.F., Alfie ri A.A. (2013). Bovine papillomavirus type 13 DNA in equine sarcoids. J. Clin. Microbiol., 51: 2167-2171.

Maruya S., Is s a J.P., Weber R.S., Rosenthal D.I., Haviland J.C., Lotan R., E1- N a g g a r A.K. (2004). Differential methylation status of tumor-associated genes in head and neck squamous carcinoma: incidence and potential implications. Clin. Cancer Res., 10: 3825-3830.

M aruy a ma R., Toy o ok a S., Toy o oka K.O., Harada K., Virmani A.K., Z o chbauer- Muller S., F arinas A.J., Vakar-Lopez F., Minna J.D., S a galow sky A., Czer$\mathrm{n}$ i a k B., G a z d a r A.F. (2001). Aberrant promoter methylation profile of bladder cancer and its relationship to clinicopathological features. Cancer Res., 61: 8659-8663.

Melnikov A., Shrestha S., Yi Q., Replogle C., Borgia J., Bonomi P., Liptay M., Ugolini D., Neri M., Verri C., Sozzi G., Levenson V. (2014). Non-small cell lung cancer can be detected and its subtypes differentiated by a blood test of methylation in cell-free DNA from plasma. JSM Biomar., 1: 1003.

Ogi K., Toyota M., Ohe-Toyota M., Tanaka N., Noguchi M., Sonoda T., Koham a G., Tok in o T. (2002). Aberrant methylation of multiple genes and clinicopathological features in oral squamous cell carcinoma. Clin. Cancer Res., 8: 3164-3171.

O sh imo Y., Nakayama H., Ito R., Kitadai Y., Yoshida K., Chay ama K., Yasui W. (2003). Promoter methylation of cyclin D2 gene in gastric carcinoma. Int. J. Oncol., 23: 1663-1670.

R Development Core Team (2011). R: A language and environment for statistical computing. R Foundation for Statistical Computing, Vienna, Austria. ISBN 3-900051-07-0, URL http:/www.R-project. org/

Rohde C., Zhang Y., Reinhardt R., Je lts ch A. (2010). BISMA - fast and accurate bisulfite sequencing data analysis of individual clones from unique and repetitive sequences. BMC Bioinformatics, 11: 230 .

S pugnardi M., Tommas i S., Dammann R., P fe if er G.P., Hoon D.S. (2003). Epigenetic inactivation of RAS association domain family protein 1 (RASSF1A) in malignant cutaneous melanoma. Cancer Res., 63: 1639-1643.

Strazzullo M., Corteggio A., A ltamura G., Francioso R., Roperto F., D'Esposi to M., B orzacchiello G. (2012). Molecular and epigenetic analysis of the fragile histidine triad tumour suppressor gene in equine sarcoids. BMC Vet. Res., 8: 30.

Virmani A.K., Rathi A., Sathyanarayana U.G., Padar A., Huang C.X., Cunnigham H.T., Farinas A.J., Milchgrub S., Euhus D.M., Gilcrease M., Herman J., 
Minna J.D., Gazdar A.F. (2001). Aberrant methylation of the adenomatous polyposis coli (APC) gene promoter 1A in breast and lung carcinomas. Clin. Cancer Res., 7: 1998-2004.

Received: 13 III 2018

Accepted: 27 VI 2018 